\title{
FTIR ABSORPTION AND STABLE NITROGEN AND CARBON ISOTOPE MICROANALYSIS OF MID-ARCHAEAN DIAMONDS FROM THE PANDA KIMBERLITE
}

\author{
Kalle Westerlund $^{1}$, Erik H. Hauri ${ }^{2}$ and John J. Gurney ${ }^{1}$ \\ ${ }^{1}$ Department of Geological Sciences, University of Cape Town, South Africa; ${ }^{2}$ Department of Terrestrial Magnetism, \\ Carnegie Institution of Washington, Washington, DC, U.S.A.
}

\section{INTRODUCTION}

A substantial amount of FTIR absorption data (mainly nitrogen content and aggregation) as well as nitrogen and carbon isotope data on diamonds from worldwide localities has been published to date (e.g. Deines et al., 1997 and references therein; Cartigny et al., 1998 and references therein). The vast majority of this data has been obtained on whole diamonds or diamond chips. Although the data has contributed substantially to the understanding of diamond formation and the nitrogen and carbon budget of the Earth, FTIR absorption and stable isotope analysis of whole diamonds or diamond chips may leave room for uncertainties. Cathodoluminescence imaging of polished diamond plates has revealed that diamonds with a highly complex internal growth structure are not unusual (e.g. Bulanova, 1995; Davies et al., 1999). Nitrogen contents in adjacent growth zones may differ by $>1000 \mathrm{ppm}$ and spurious nitrogen content-nitrogen aggregation relationship may result from FTIR analysis of multiple growth zones. Further, within-diamond nitrogen and carbon stable isotope compositions may vary by $>10 \%$ (e.g. Bulanova et al., 2002). From this, it is obvious that FTIR and stable isotope microanalysis of crystallographically controlled diamond plates can reveal information that may otherwise be hidden.

A set of diamonds from the Panda kimberlite, Slave craton is of mid-Archaean age as revealed by the Re-Os isotope systematics of their sulfide inclusions (Westerlund et al., this volume). The very high Os and $\mathrm{Ni}$ contents of the sulfides are compatible with a peridotitic paragenesis. Prior to the extraction of the sulfides, the ten diamonds (and another two diamonds carrying chromite inclusions) were polished into plates along the 110 crystal plane. Cathodoluminescence imaging and detailed FTIR absorption analysis and nitrogen and carbon isotope spot analysis using SIMS were performed along traverses across the plates. The results of these analyses are presented here.

\section{ANALYTICAL TECHNIQUES}

FTIR absorption spectra were measured with a Nicolette Magna-IR 760 spectrometer at Anglo American Research Laboratories in Johannesburg and at the Department of Geology, University of Cape Town using a Nicolette Magna-IR 560 spectrometer. Details of the estimation of the nitrogen aggregation and content as well as mantle residence temperatures for the diamonds are given in Mendelssohn and Milledge (1995). The stable isotope analysis was perfumed at the Department of Terrestrial Magnetism using a Cameca $6 \mathrm{f}$ ion-probe. The analytical technique is detailed in Hauri et al. (2002). The total $1 \sigma$ error for the $\delta^{13} \mathrm{C}$ values is about $\pm 0.3 \%$. For $\delta^{15} \mathrm{~N}$ the reproducibility is about $\pm 1 \%$ while the accuracy is about $\pm 3 \%$ due to the heterogeneity of the standard.

\section{NITROGEN CONTENT AND AGGREGATION}

Cathodoluminescence imaging of the diamond plates show mainly simple uninterrupted octahedral growth of type I (nitrogen carrying) diamond while some specimen display centrally located zones of nonluminescent, type II (nitrogen deficient) diamond (Figure 1). Apart from some "internal" type II diamond, the nitrogen content generally (but not exclusively) decreases continuously and distinctly from the cores (500-950 ppm) to the rims (20-100 ppm). Individual diamonds display a range in nitrogen content of up to $700 \mathrm{ppm}$. The nitrogen contents are fairly high for peridotitic diamonds with an average of $416 \mathrm{ppm}$ compared to and average of $148 \mathrm{ppm}$ for 242 peridotitic diamonds from Roberts Victor, Finch, Premier, Koffiefontein, Jagersfontein, Orapa, Jwaneng on the Kaapvaal craton (Deines et al., 1987, 1989, 1991, 1993, 1997).

At mantle temperatures, single nitrogen atoms incorporated in diamond at growth will combine to form A aggregates (pairs of nitrogen atoms on adjacent lattice sites) and further to form B aggregates (four nitrogen atoms arranged around a vacancy) (e.g. Evans, 


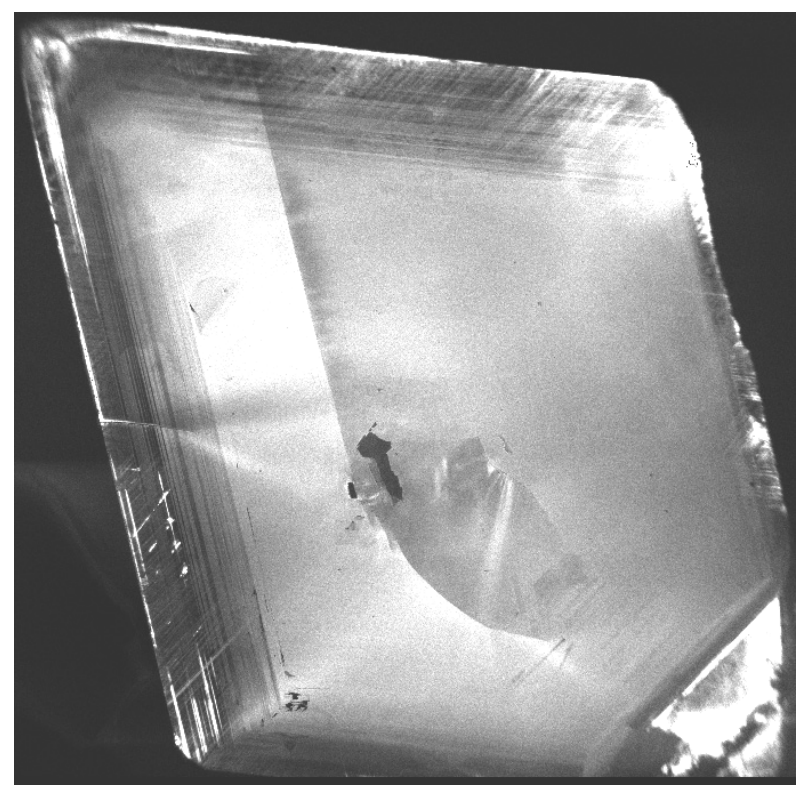

Figure 1: Cathodoluminescence image of a diamond plate showing regular octahedral type I diamond growth with subordinate type II diamond in the centre.

1992). Nitrogen aggregation is highly temperature sensitive. The $\mathrm{A} \rightarrow \mathrm{B}$ reaction obeys second-order kinetics and when the activation energy is known, the time-averaged mantle residence temperature $\left(\mathrm{T}_{\mathrm{AV}}\right)$ may be derived for an assumed time. The level of aggregation (the amount of the total nitrogen present as $\mathrm{B}$ aggregates) is plotted versus the nitrogen content in Figure 2. Data from a previous study on Panda

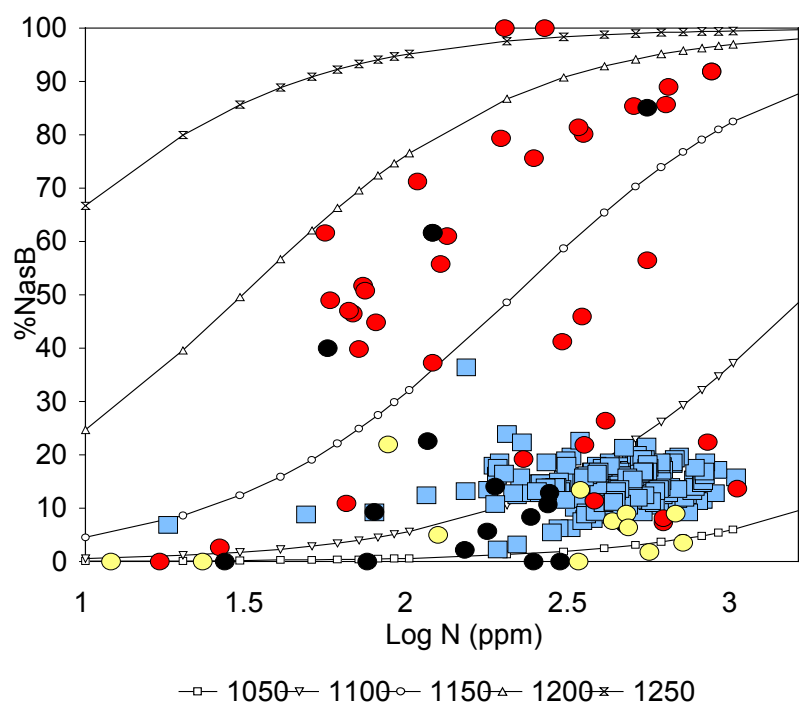

Figure 2: Nitrogen aggregation and content for Panda diamonds. Blue squares - this study; Circles - Stachel and Harris, in press. Red, Black and Yellow are silicate-, chromite- and sulfide-bearing respectively. Inserted lines are isotherms for an assumed time of $3 \mathrm{Ga}$. diamonds (Stachel and Harris, in press) divided up into silicate-, chromite- and sulfide-bearing diamonds is also shown. Inserted are isotherms for an assumed time of 3 Ga. The analyses from the present study yield largely low levels of aggregation and plot mainly below the $1100{ }^{\circ} \mathrm{C}$ isotherm. The data from the present study scattering above the $1100{ }^{\circ} \mathrm{C}$ isotherm over-estimates the temperature due to partial sampling of type II diamond and the effect of hydrogen on the estimation of the level of aggregation. Apart from the scatter to higher temperatures, data from individual diamonds form trends parallel to the isotherms (Figure 3). Comparing the data in the present study to Stachel and Harris (in press), it is apparent that: 1. The bulk of the chromite- and sulfide-bearing diamonds of Stachel and Harris (in press) have similar nitrogen content and similar to slightly lower $\mathrm{T}_{\mathrm{AV}}$ compared to the diamonds in the present study; 2. Some of the silicate-bearing diamonds of Stachel and Harris (in press) conform to our data while the bulk plot along the $1075{ }^{\circ} \mathrm{C}$ isotherm.

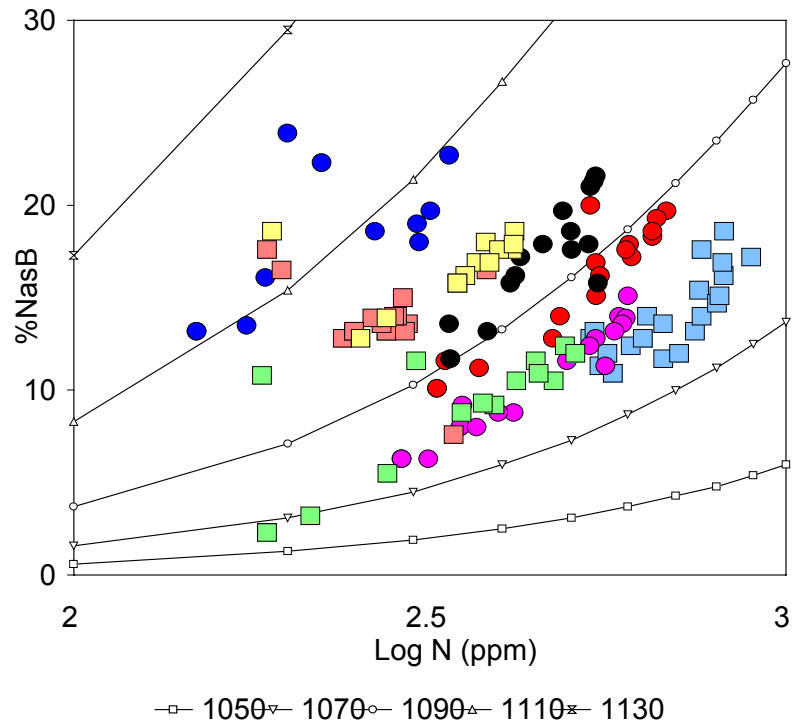

Figure 3: Nitrogen aggregation and content for individual Panda diamonds (For clarity, only eight of the analysed diamonds are plotted).

\section{NITROGEN AND CARBON STABLE ISOTOPES}

The majority of the diamonds are highly depleted in ${ }^{15} \mathrm{~N}$ and they exhibit a range in $\delta^{15} \mathrm{~N}$ of -25.6 to $-6.8 \%$. Mean and median values for all sixty-four analyses are about $-17 \%$. However, only two individual diamonds have median values coinciding with the grand mean. Individual diamonds display ranges in $\delta^{15} \mathrm{~N}$ from about $0.5 \%$ to $8 \%$. The lowest observed $\delta^{15} \mathrm{~N}$ values are similar what has been observed for some diamonds 
from Fuxian, P.R. China (Cartigny et al., 1997). The bulk of the analyses form a broad negative trend between nitrogen content and $\delta^{15} \mathrm{~N}$ (Figure 4). Some individual diamonds plot along parts of this trend from higher nitrogen contents and lighter nitrogen isotope compositions in the core zone to lower nitrogen contents and heavier isotope compositions in the rim. Other individual diamonds show more irregular systematics within this broad trend and one analysis from each of two diamonds plot away from this trend (Figure 4). The analyses from diamonds PD1 and PD7 display similar negative trends, but they are displaced to higher and lower $\delta^{15} \mathrm{~N}$ respectively.

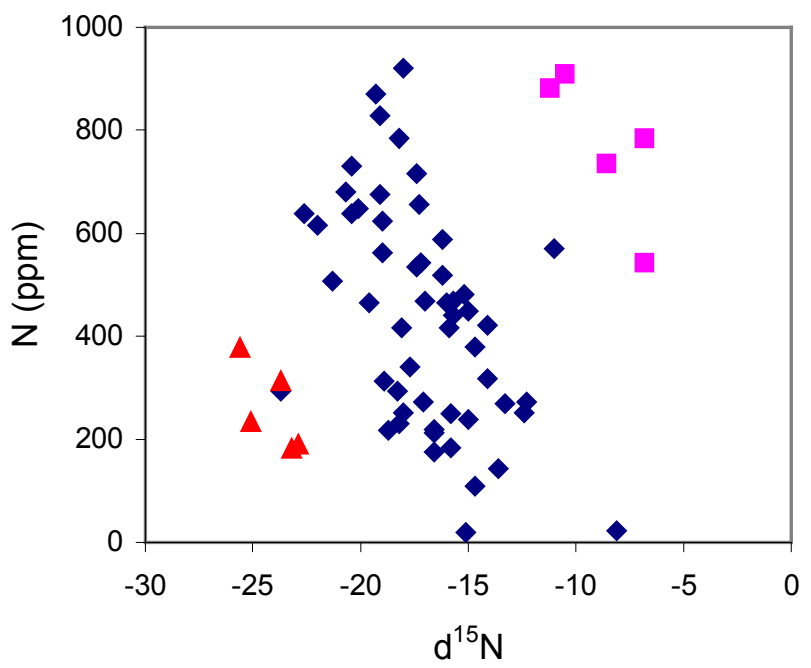

Figure 4: Nitrogen concentration versus isotopic composition. Blue diamonds - data from ten diamonds plotted together, Purple squares - diamond PD1 and Red triangles diamond PD7.

The carbon isotope compositions $\left(\delta^{13} \mathrm{C}\right)$ of the diamonds ranges from about -10 to $0 \%$ (Figure 5). This range spans the whole range observed for peridotitic diamonds from worldwide locations excluding some rare encounters of lighter carbon isotopic compositions (e.g. Kirkley et al., 1991). The $\delta^{13} \mathrm{C}$ values from the sixty-eight analyses show a close to normal distribution with a mean value of $-5.5 \%$, which coincides with the generally accepted value for the carbon isotope composition of the present-day primitive mantle. Individual diamonds display a range in $\delta^{13} \mathrm{C}$ of up to $-7.1 \%$ (PD6) and the within-diamond variations are always highly irregular spatially. The carbon isotope compositions do not correlate with the nitrogen isotope compositions or nitrogen contents.

\section{DISCUSSION AND CONCLUSIONS}

The continuous octahedral internal growth zoning of the diamonds, and the generally continuous decrease (rather than abrupt changes) in nitrogen content from core to rim are suggestive of a single and relatively brief diamond formation event. Since individual diamonds plot parallel to the isotherms in Figure 3, diamond cores and rims display similar time-averaged mantle temperatures also indicative of a confined diamond formation event followed by long-term storage of the diamonds in the lithosphere. On the basis of mineral chemical compositions, Stachel and Harris (in press) concluded that Panda diamonds studied for silicate inclusions originate from a moderately meltdepleted deeper part of the lithosphere commencing at a depth of about $140 \mathrm{~km}$ (Griffin et al., 1999). The highly elevated time-averaged mantle residence temperature of these diamonds also indicates residence in the deeper part of the lithosphere. The diamonds here studied (and the chromite- and sulfide-bearing diamonds of Stachel and Harris, in press) are distinctly "cooler" than the silicate-bearing population. This implies that the Panda kimberlite carries at least two separate diamond populations, which formed in widely different mineralogical/chemical environments. Further, the nitrogen aggregation implies that the diamonds here studied originate from a relatively shallow part of the diamondiferous lithosphere. The host environment may correspond to the deepest part of the ultra-depleted shallow lithospheric mantle, which has seen a significantly higher degree of melt-depletion than the deeper Slave lithosphere (Griffin et al., 1999).

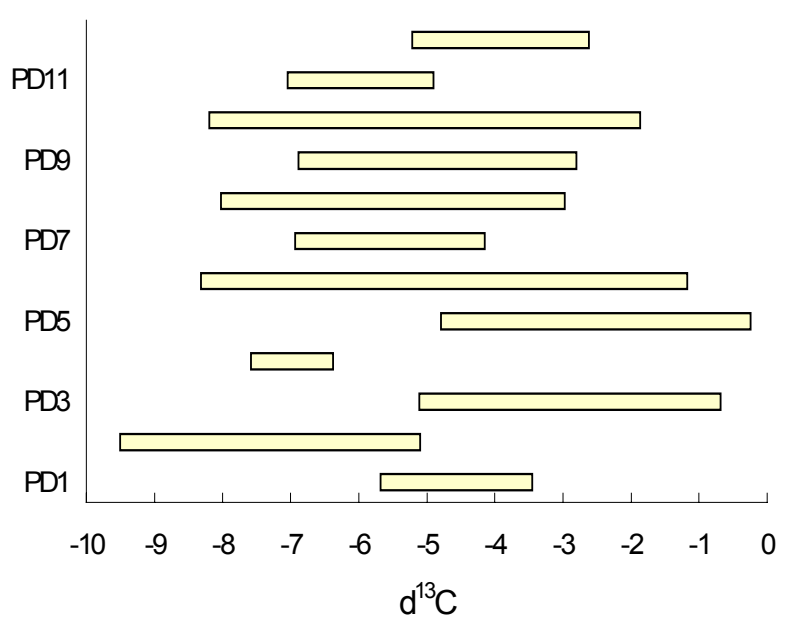

Figure 5: Ranges in carbon isotope composition for individual diamonds PD1 to PD12. 
Together with the cathodoluminescence and FTIR absorption data discussed above, the observed negative correlation(s) between nitrogen content and isotope composition in the diamonds suggests that a single process in the immediate diamond formation environment is responsible for the $\mathrm{N}-\delta^{15} \mathrm{~N}$ evolution. Invoking a distillation process, a fractionation factor of 1.005-1.006 would be required $(\mathrm{N}<50$ ppm analyses are excluded from estimation due to the large analytical errors in both concentration and isotopic composition). Fractionation caused by the preferential incorporation of ${ }^{14} \mathrm{~N}$ into diamond is the opposite to the general observation that small and highly charged atoms in a well-ordered structure prefer the heavier isotope. However, unidirectional reactions should yield enrichment of the lighter isotope in the product (here diamond) and kinetic isotope fractionation at diamond formation may explain the observations. Fractionation between simple nitrogen-bearing molecules above 1000 ${ }^{\circ} \mathrm{C}$ is less than $1.5 \%$ (Richet et al., 1977). Although slightly high, the derived fractionation factor is not unrealistic considering the unusual chemical properties of diamond and that phase relations during the incorporation of nitrogen are unknown. It may also be considered that fractionation is induced by the continuous escape of a volatile phase enriched in ${ }^{14} \mathrm{~N}$ (e.g. $\mathrm{N}_{2}$ or $\mathrm{NH}_{3}$ ) during diamond formation, which would cause a concurrent depletion in nitrogen and enrichment in ${ }^{15} \mathrm{~N}$ in the diamond forming fluid. Alternatively, the observed trend(s) may be ascribed changing $\mathrm{P}-\mathrm{T}-\mathrm{fO}_{2}$ conditions (Deines, 1980; Deines et al., 1989). Already small shifts in temperature or $\mathrm{fO}_{2}$ can produce up to a few per mil shift in the diamondfluid nitrogen isotope fractionation factor. Further, a decrease in $\mathrm{fO}_{2}$ may yield a negative correlation between nitrogen content and $\delta^{15} \mathrm{~N}$ as observed in the present study.

While the negative trends in Figure 4 may be explained by fractionation during diamond growth, the different isotopic compositions at the highest nitrogen content for each trend is proposed to be a signature of the source fluid. The observed $\mathrm{N}-\delta^{15} \mathrm{~N}$ correlation is likely obscured in combustion analysis of large sets of whole diamonds or diamond chips due to a combination of averaging $\delta^{15} \mathrm{~N}$ from different growth zones and the presence of different source fluids. However, similar trends have been observed before (Javoy et al., 1984; Boyd et al., 1987) with a range in $\delta^{15} \mathrm{~N}$ from -1.8 to $+13.4 \%$ in the latter study. This suggests that individual diamond populations may exhibit a limited range in $\delta^{15} \mathrm{~N}$ caused by diamond formation related fractionation while the complete range in $\delta^{15} \mathrm{~N}$ for diamonds world-wide ( $-25.6 \%$; this study to $+16.6 \%$;
Boyd and Pillinger, 1994) is mainly related to different source compositions. It may be speculated that the range in source fluid nitrogen isotope compositions is related to mixing of two (or more) distinctive sources. As noted by Cartigny et al. (1997) who recorded $\delta^{15} \mathrm{~N}$ values down to $-24.2 \%$ in diamonds from Fuxian China, $\delta^{15} \mathrm{~N}<-25 \%$ is characteristic of enstatite chondrite which lends support to the heterogeneous accretion theory. It is interesting to note that the Os isotope composition of the primitive upper mantle is suggestive of late accretion from enstatite or ordinary chondrites (Meisel et al., 1996, 2001).

Although the mean $\delta^{13} \mathrm{C}$ of the diamonds $(-5.5 \%)$ is similar to the $\delta^{13} \mathrm{C}$ of the present-day and likely the Archaean mantle, the observed range even within diamonds is indicative of significant carbon isotope heterogeneity in the diamond formation environment. High-temperature isotope fractionation between reduced carbon species during diamond formation is plausible (e.g. Deines, 1980) but the current data shows that potential carbon isotope fractionation is not coupled to processes in the immediate diamond formation event governing the nitrogen content and nitrogen isotope characteristics. The highly irregular variations of $\delta^{13} \mathrm{C}$ within diamonds are difficult to reconcile with carbon isotope fractionation during diamond growth and the variable $\delta^{13} \mathrm{C}$ may be a source characteristic.

\section{REFERENCES}

Boyd, S.R., Pillinger, C.T., 1994. A preliminary study of ${ }^{15} \mathrm{~N} /{ }^{14} \mathrm{~N}$ in octahedral growth form diamonds. Chem. Geol., 116, 43-59.

Bulanova, G.P., 1995. The formation of diamond. J. Geochem. Expl. 53, 1-23.

Bulanova, G.P., Pearson, D.G., Hauri, E.H., Griffin, B.J., 1999. Carbon and nitrogen isotope systematics within a sector growth diamond from the Mir kimberlite, Yakutia. Chem. Geol., 188, 105-123.

Cartigny, P., Boyd, S.R., Harris, J.W., Javoy, M., 1997. Nitrogen isotopes in peridotitic diamonds from Fuxian, China: the mantle signature. Terra Nova, 9, 175-179.

Cartigny, P., Harris, J.W., Phillips, D., Girard, M., Javoy, M., 1998. Subduction-related diamonds? - The evidence for a mantle-derived origin from coupled $\delta^{13} \mathrm{C}-\delta^{15} \mathrm{~N}$ determinations. Chem. Geol. 147, 147-159. 
Davies, R.M., O’Reilly, S.Y., Griffin, W.L., 1999. Growth structures and nitrogen characteristics of group B alluvial diamonds from Bingara and Wellington, Eastern Australia. Proc. 7 Int. Kimb. Conf. Cape Town, South Africa, Vol. 1, pp. 156-163.

Deines, P., 1980. The carbon isotopic composition of diamonds: relationship to diamond shape, color, occurrence and vapor composition. Geochim. Cosmochim. Acta 44, 943-961.

Deines, P., Harris, J.W., Gurney, J.J., 1987. Carbon isotopic composition, nitrogen content and inclusion composition of diamonds from the Roberts Victor kimberlite, South Africa: Evidence for ${ }^{13} \mathrm{C}$ depletion in the mantle. Geochim. Cosmochim. Acta 51, 12271243.

Deines, P., Harris, J.W., Spear, P.M., Gurney, J.J., 1989. Nitrogen and ${ }^{13} \mathrm{C}$ content of Finch and Premier diamonds and their implications. Geochim. Cosmochim. Acta 53, 1367-1378.

Deines, P., Harris, J.W., Gurney, J.J., 1991. The carbon isotopic composition of lithospheric and asthenospheric diamonds from the Jagersfontein and Koffiefontein kimberlite, South Africa. Geochim. Cosmochim. Acta 55, 2615-2625.

Deines, P., Harris, J.W., Gurney, J.J., 1993. Depth-related carbon isotope and nitrogen concentration variability in the mantle below the Orapa kimberlite, Botswana, Africa. Geochim. Cosmochim. Acta 57, 2781-2796.

Deines, P., Harris, J.W., Gurney, J.J., 1997. Carbon isotope ratios, nitrogen content and aggregation state, and inclusion chemistry of diamonds from Jwaneng, Botswana. Geochim. Cosmochim. Acta 61, 39934005.

Evans, T., 1992. Aggregation of nitrogen in diamond. In: Field, J.E. (Ed.), The properties of natural and synthetic diamond. Academic Press, pp. 259-290.

Griffin, W.L., Doyle, B.J., Ryan, C.G., Pearson, N.J., O’Reilly, S.Y., Davies, R., Kivi, K., Van Achterberg, E., Natapov, L., 1999. Layered mantle lin the Lac de Gras area, Slave craton: Composition, structure and origin. J. Petrol., 40, 705-727.

Hauri, E.H., Wang, J., Pearson, D.G., Bulanova, G.P., 2002. Microanalysis of and $\mathrm{N}$ abundances in diamonds by secondary ion mass spectrometry. Chem. Geol., 185, 149-163.

Javoy, M., Pineau, F. Demaiffe, D., 1984. Nitrogen and carbon isotopic composition in the diamonds of Mbuji Mayi (zaire). Earth Planet. Sci. Lett., 68, 399-412.
Kirkley, M.B., Gurney, J.J., Marshall, L.O., Hill, S.J., Daniels, L.R., 1991. The application of C isotope measurements to the identification of sources of $\mathrm{C}$ in diamonds: a review. Appl. Geochem., 6, 477-494.

Meisel, T., Walker, R.J., Morgan, J.W., 1996. The osmium isotopic composition of the Earth's primitive upper mantle. Nature, 383, 517-520.

Meisel, T., Walker, R.J., Irving, A.J., Lorand, J-P., 2001. Osmium isotopic compositions of mantle xenoliths: A global perspective. Geochim. Cosmochim. Acta, 8, 1311-1323.

Mendelssohn, M., Milledge, H.J., 1995. Geological significant informationfrom routine analysis of the mid-infrared spectra of diamonds. Int. Geol. Rev., 37, 95-110.

Richet, P., Bottinga, Y., Javoy, M., 1977. A review of hydrogen, carbon, nitrogen, oxygen, sulphur and chlorine stable isotope fractionation among gaseous molecules. Annu. Rev. Earth Planet. Sci., 5, 65-110.

Stachel, T., Harris, J.W., in press. Peridotitic inclusions in diamonds from the Slave and the Kaapvaal cratons similarities and differences based on a preliminary data set. Lithos.

Contact: KJ Westerlund, Department of Geological Sciences, University of Cape Town, Private Bag, Rondebosch, 7700, South Africa, E-mail: Kalle@geology.uct.ac.za 